\title{
Premammillary Artery Infarction after Microsurgical Clipping of Unruptured Posterior Communicating Artery Aneurysm: Risk Factors, Surgical, and Anatomical Considerations
}

JONG MIN LEE ( $\square$ gogmgek@naver.com )

Asan Medical Center https://orcid.org/0000-0003-2324-8706

Joon Ho Byun

University of Ulsan

Seungjoo Lee

University of Ulsan

Eun Suk Park

University of Ulsan College of Medicine

Jung Cheol Park

University of Ulsan

Jae Sung Ahn

University of Ulsan

Wonhyoung Park

University of Ulsan

\section{Research Article}

Keywords: Intracranial aneurysm, Posterior communicating artery aneurysm, clipping, infarction

Posted Date: November 10th, 2021

DOI: https://doi.org/10.21203/rs.3.rs-1018024/v1

License: (c) (i) This work is licensed under a Creative Commons Attribution 4.0 International License. Read Full License

Version of Record: A version of this preprint was published at Neurosurgical Review on March 19th, 2022. See the published version at https://doi.org/10.1007/s10143-022-01734-2. 


\section{Abstract \\ Purpose}

Posterior communicating artery (PCOA) aneurysm is common and sometimes requires microsurgery; however, as data on premammillary artery (PMA) infarction after clipping is scarce, we retrospectively reviewed cases of post-clipping PMA infarction to analyze incidence, independent risk factors of infarction, and anatomical considerations.

\section{Methods}

Data from 569 consecutive patients who underwent microsurgical clipping for unruptured PCoA aneurysm between January 2008 and December 2020 were included. Patients were categorized into the normal or the PMA infarction group. Statistical analyses and comparisons between the two groups were used to determine the influence of various factors.

\section{Results}

The normal group included 515 patients while the PMA infarction group had 31 . The mean length of hospital stay was significantly longer in the PMA infarction group $(10.3 \pm 9.1$ days $)$ than in the normal group $(6.5 \pm 6.4$ days; $p<0.0001)$. The distribution of Glasgow Outcome Scale (GOS) at discharge was significantly different between the two groups ( $p \leq$ $0.0001)$ but was not so at 6 months after discharge $(p=0.0568)$. Multivariate-logistic-regression analysis identified aneurysm size (odds ratio [OR], 1.194; 95\% confidence interval [Cl], 1.08-1.32; $p=0.0005$ ) and medial direction of aneurysm (OR, 4.615; 95\% Cl, 1.224-17.406; $\mathrm{p}=0.0239)$ as independent risk factors of post-clipping PMA infarction.

\section{Conclusions}

Surgeons must beware of PMA infarction after clipping of large aneurysms that are medial in direction. Intraoperative verification of the patency of the PCoA and the PMA from various angles using various intraoperative methods can reduce morbidity due to PMA infarction.

\section{Introduction}

Aneurysms originating at or near the posterior communicating artery ( $\mathrm{PCOA}$ ) are one of the most common types of intracranial aneurysms [28, 29], and recently, many such aneurysms are being treated endovascularly due to significant developments such as stents for coil embolization and flow diverters. Concurrently, challenging cases that are difficult to treat endovascularly include aneurysms that are large in size, have a broad neck, or are incorporated in the PCoA, especially fetal type PCoA. Characteristics of these PCoA aneurysms, which often necessitate the use of complex endovascular techniques and devices, such as multiple microcatheters, stents, balloon, and even flow diverters, render them susceptible to incomplete treatment, and result in higher recurrence rate, greater thromboembolic risk, and retreatment. Nevertheless, in these aneurysms, microsurgery represents a useful treatment modality with many advantages, and attention must be paid to not only to complete obliteration of the aneurysm but also to preservation of the parent artery and the perforating arteries. Notable vascular structures during PCoA aneurysm surgery are the anterior choroidal artery, the PCoA itself, and perforating arteries arising from the PCoA, i.e., the anterior thalamoperforating arteries. Among them, the PMA is generally the largest and the most frequently seen perforating branch of the PCoA. The PMA, also called as the tuberothalamic artery, supplies the posterior hypothalamus, the mammillothalamic tract, the anterior thalamus (nucleus ventralis anterior, ventrolateral and dorsomedial nucleus, and reticular nucleus), the anteromedial part of the optic tract, the inferomedial tip of the head of the caudate nucleus, the genu, and a part of the 
posterior limb of the internal capsule $[8,12]$. It is essential to identify and preserve the anatomy of the PCoA and the anterior thalamoperforating arteries for good neurological prognosis, and adequate patient management requires differentiating between symptoms due to other lesions and those caused by a compromised PCoA or its perforators.

Several reports have described PMA infarction after PCoA aneurysm clipping, but they include patients with subarachnoid hemorrhage, and only a few reports are available on outcomes after microsurgical clipping for unruptured PCoA aneurysm. Therefore, we retrospectively reviewed cases of PMA infarction after microsurgical clipping of unruptured PCoA aneurysm to analyze its incidence, independent risk factors, and anatomical considerations.

\section{Material And Methods}

The study protocol and the retrospective review of medical records were approved by the institutional review board of the Asan Medical Center, University of Ulsan College of Medicine, Seoul, Korea. ( S2021-0693-0001).

\section{Study population}

Between January 2008 to December 2020, 8006 patients with unruptured intracranial aneurysm were treated in our institution. Of these, 2991 were treated endovascularly while 5015 patients underwent transcranial surgery. From these, we included 569 consecutive patients who underwent microsurgical clipping for unruptured PCoA aneurysm. Clinical and radiological characteristics of the patients and the unruptured PCOA aneurysms were retrospectively reviewed using the institutional Electronic Medical Records (EMR) database, picture archiving, and communication systems. In patients without a definite PCoA upon transfemoral cerebral angiography (TFCA) examination, those with a small branch around the aneurysm neck, consistent with hypoplastic PCoA or PMA, were included [8, 21]. We excluded patients (1) with subarachnoid hemorrhage, (2) who did not undergo direct aneurysmal neck clipping such as wrapping, coagulation or bypass, and (3) without proper radiological follow up for more than 6 months after surgery.

\section{Clinical \& radiological data collection and evaluation}

Information on age, sex, past medical history, including smoking status, hypertension, diabetes mellitus, hyperlipidemia, and previous stroke history, was obtained through the EMR database. Previous stroke was defined as cerebral infarction observed on MR or computed tomography (CT) study before surgery.

All patients underwent preoperative computed tomography angiography (CTA) and transfemoral cerebral angiography (TFCA) to determine the morphological characteristics of the aneurysm. Aneurysm size was defined as maximal dome size on three-dimensionally reconstructed images. CTA scans were performed with a slice thickness of $0.5 \mathrm{~mm}$ and were acquired as axial images. Based on thin section CTA images or the 3-dimensional images, a line parallel to the midline was drawn at the junction of the internal carotid artery (ICA) and the PCOA. Another line perpendicular to previous line was drawn horizontally at the junction of the ICA and the PCOA. Next, the third and the fourth lines, which equally divided the angle between the parallel and the perpendicular lines, were drawn posterolaterally and posteromedially (Figure 1). Based on these third and fourth lines, a projection of the aneurysm was categorized as being in the posterior, lateral, or medial direction. Fetal-type PCoA was defined as that which has a diameter that is either identical to or larger than the P1 segment [10]. The hypoplastic type was defined as when PCoA was not apparent on angiography. All others were classified as the adult type [7]. To minimize bias, the type of PCoA and direction of the aneurysm were determined by a neurosurgeon and a neuroradiologist who were unrelated to this study.

All patients who underwent microsurgical clipping were evaluated using CT and CTA immediately after surgery. In the absence of a specific neurological deficit, all patients were assessed by brain CT on day 3 after surgery. If additional postoperative angiographic evaluation was needed, in cases with multiple aneurysms or a large aneurysm, if clear identification of residual lesions or parent arteries upon CTA was difficult due to artifacts secondary to the presence of

Page $3 / 20$ 
multiple clips, if complications such as infarction or hemorrhage occurred, or if neurological symptoms that could not be explained by CTA appeared after surgery, TFCA was optionally performed on day 3 after surgery. Diffusion-weighted magnetic resonance imaging (DW-MRI) to confirm cerebral infarction was performed in all patients with a neurologic deficit after surgery. In asymptomatic patients, postoperative infarction was defined as a low-density area compatible with a specific vascular supply territory on CT acquired on the day 3 after surgery (Figure 2).

\section{Surgical management strategy and Outcome assessment}

Clipping procedures were performed by 3 certified attending surgeons with key concept of approaches and surgical strategies shared among the surgeons. Conventional frontotemporal craniotomies and pterional approaches were used in all cases. The YASARGIL aneurysm clip system (Aesculap AG\&Co., Tuttlingen, Germany) was employed in all patients. Given the effect of clip placement on the parent artery, data from patients provided a standard/mini clip or a fenestration clip were analyzed separately (Figure 3,4 ). If proximal control seemed difficult, exposure of the cervical ICA or extradural/intradural anterior clinoidectomy was performed $[19,26]$. As per institutional norms, temporary clipping did not exceed 5 minutes. In most cases, patency of distal flow in the parent artery and in the perforators was confirmed using indocyanine green (ICG) video angiography and microvascular doppler, along with simultaneous monitoring somatosensory evoked potentials (SEPS) and motor evoked potentials (MEPs). As intraoperative evoked potential (EP) monitoring was introduced only in 2012, MEP/SEP could be monitored only in 465 of the 569 patients (81.7\%). All patients were evaluated at the time of admission, at discharge, and at 6 months after discharge using the Glasgow Outcome Scale (GOS). The primary end point of this study was postoperative PMA infarction. Secondary end points were duration of hospitalization, and GOS scores.

\section{Statistical analysis}

We intended to analyze how a patient's baseline characteristics, aneurysm factors including size and direction, type of posterior communicating artery (fetal, hypoplastic, or adult type), use of a fenestration clip, intraoperative rupture, location and extent of cerebral infarction, hospital stay, and GOS at discharge and 6 months after surgery, affected postoperative infarction occurrence. For accurate statistical analysis of the factors affecting the occurrence of a PMA infarction, patients were divided into a normal group and a PMA infarctions group; the latter group comprised patients with a postoperative infarction in the PMA area. We investigated statistically significant differences between the two groups for the variables described. Categorical variables were expressed as frequencies with percentages, while continuous variables used mean and standard deviation. Continuous variables were also subjected to analysis of variance and student $t$-test, while Chisquared and fisher's exact tests were used for categorical variables. We used a multiple-logistic-regression model with significant variables from univariate analyses to identify independent predictors of postoperative PMA infarction. In cases with a fenestration clip, hemodynamic infarction due to ICA narrowing may be induced regardless of PMA infarction. Further, because of the tendency of larger aneurysms to require more fenestration clips, they were excluded from the multiple regression model. Variables identified as significant during univariate analysis were inserted into a backward stepwise logistic-regression model to identify variables that were independently associated with infarction. All reported $P$ values are two sided, with $\mathrm{P}<0.05$ considered statistically significant. Statistical analyses were performed using SAS package (version 9.4, SAS Institute, Cary, USA).

\section{Results}

Among the 569 patients (mean age, $60.1 \pm 8.9$ years) included in this study, 54 patients $(9.4 \%)$ showed radiographical complications on follow up, with 10 cases of traction injury (1.7\%), 1 case of hemorrhage complication ( $0.1 \%)$, and 43 cases of ischemic complications (7.5\%). Next, among the 43 patients with ischemic complications, 31 had a PMA infarction (5.4\%), while the other 12 patients comprised 2 cases of middle cerebral artery (MCA) territory infarction after concomitant MCA aneurysm clipping, 2 cases of hemodynamic infarction caused by narrowing of the ICA due to the use

Page $4 / 20$ 
of a fenestration clip, 4 cases of anterior choroidal artery infarction, 2 cases of recurrent artery infarction because of concomitant anterior communicating artery aneurysm clipping, and 2 cases of embolic infarction. We divided patients into two groups, viz., the normal group and the PMA infarctions group. For accurate comparison, we excluded 23 patients with traction injury, postoperative hemorrhagic complications, and infarction in an artery other than the PMA (recurrent artery of Heubner, MCA territory, hemodynamic infarction, anterior choroidal artery, and embolic infarction). Thus, there were 515 cases in the normal group and 31 in the PMA infarction group. Baseline characteristics of the included cases are summarized in Table 1. Mean age in the PMA group was $63.1 \pm 6.4$ years and was significantly greater than that of the normal group ( $59.8 \pm 9.1$ years; $p=0.011)$. There was no significant difference between the two groups in male: female ratio or the prevalence of hypertension, diabetes mellitus, hyperlipidemia, smoking, stroke history, aneurysm location, or intraoperative rupture. Mean length of hospital stay was $10.3 \pm 9.1$ days in the PMA infarction group and was significantly longer than that of the normal group ( $6.5 \pm 6.4$ days; $p<0.0001)$. Aneurysm size was also significantly larger in the PMA group $(4.9 \pm 2.4 \mathrm{~mm}$ vs $7.3 \pm 4.7 \mathrm{~mm}, p<0.0001)$. In the normal group, adult type of PCoA was predominant $(42.7 \%)$, whereas in the PMA infarction group, hypoplastic PCoA was most frequently seen (42\%). Medial direction was most frequently seen in the PMA group compared to the normal group (19.3\% vs 3.7\%), and while GOS at discharge was significantly different between the two groups $(p=<0.0001)$, it was not so at 6 months after discharge $(p=0.0568)$.

Details of patients with PMA infarction are summarized in Table 2. Of these, 9 patients $(9 / 31 ; 29 \%)$ showed postoperative neurological symptoms while $22(22 / 31 ; 71 \%)$ had no specific neurologic symptoms. Motor weakness was observed in four patients (patients \# 2,8,17,27), and of these, patient 2 had undergone simultaneous clipping of an anterior communicating artery aneurysm; thus, we hypothesized that the weakness was due to damage at the recurrent artery of Heubner. The other three patients had an infarction in the posterior limb of the internal capsule. Postoperative PMA infarction occurred in 5 of the 87 patients (5.7\%) who had undergone microsurgical clipping before EP monitoring was introduced. Similarly, postoperative PMA infarction occurred in 26 of 459 (5.6\%) patients who had undergone clipping after EP monitoring was introduced, and there was no significant difference in the incidence of PMA infarction between the group that underwent or did not undergo EP monitoring $(p=0.9)$.

Univariate analysis found aneurysm size, use of fenestration clip, type of PCoA, and aneurysm direction to be significant variables (Table 3), while multivariate-logistic-regression analysis identified only size of aneurysm (odds ratio [OR], 1.194; $95 \%$ confidence interval [Cl], 1.08-1.32; $\mathrm{p}=0.0005)$ and medial direction aneurysm (OR, 4.615; 95\% $\mathrm{Cl}, 1.224-17.406 ; \mathrm{p}=$ 0.0239 ) as independent risk factors of PMA territory infarction after clipping of an unruptured aneurysm at the origin of PCoA. (Table 4)

\section{Discussion}

The PCoA arises from the posteromedial surface of the communicating segment of ICA and courses medially and inferiorly such that it bisects the ICA into an ophthalmic segment and a communicating segment. Typically, 2-14 perforators arise from the PCoA during its course [8,21], and such arteries are called the anterior thalamoperforating arteries. Among them, the PMA is generally the largest and the most frequently seen perforating branch that penetrates the paramedian perforating substance, which is a triangular space limited by the mammillary body and tuber cinerum medially, the optic tract anterolaterally, and the cerebral peduncle posterolaterally [8, 24]. PMA, also called as the tuberothalamic artery, is known to supply the posterior hypothalamus, the mammillothalamic tract, the anterior thalamus (nucleus ventralis anterior, ventrolateral and dorsomedial nucleus, and reticular nucleus), the anteromedial part of the optic tract, the inferomedial tip of the head of the caudate nucleus, the genu, and a part of the posterior limb of the internal capsule $[8,12]$. Further, it is known that the PMA originates from the superior and lateral surface of the PCoA, that it courses superiorly, laterally, and posteriorly, and that the majority of the PMAs originate from the middle segment of PCoA $[1,8,12,20,21]$. 
Only a few reports have described PMA infarction after PCoA aneurysm clipping. Even though Tanabe et al. have reported outcomes from 183 patients who had undergone microsurgical clipping of a PCoA aneurysm, a majority of these patients (60.1\%) presented with subarachnoid hemorrhage, which is in contrast to the patients in our cohort. Furthermore, of the 183 patients who underwent PCoA aneurysm clipping in that study, 22 patients (12\%) suffered infarction in a perforator originating from the PCoA [27], and among unruptured PCoA aneurysm patients, 2 out of 73 patients (2.7\%) experienced perforator infarction after clipping. This small sample size of the perforator infarction group precluded detailed analysis of associated risk factors. Also, in patients with subarachnoid hemorrhage, infarction may occur due to vasospasm secondary to hemorrhage, rather than other than factors such as aneurysm characteristics, PCoA type, or clipping strategy; hence, it is difficult to clearly determine risk factors of PMA infarction after clipping of unruptured PCoA aneurysm from the study of Tanabe et al. In our cohort, the overall incidence of PMA infarction after microsurgical clipping for unruptured PCoA aneurysm was about $5 \%$, and among them, while 22 patients were asymptomatic, five showed postoperative motor weakness and four patients had postoperative confusion; thus, the incidence of symptomatic PMA infarction was about $1.5 \%$. Further, symptomatic patients tended to have a wider infarction area with corticospinal tract involvement. Presumably, in cases of asymptomatic infarction, blood vessels other than the PMA, such as the lenticulostriate artery or the anterior choroidal artery, form anastomoses with the internal capsule or basal ganglia, implying a relatively smaller extent of infarction. Additionally, while Tanabe et al. excluded patients treated with a fenestration clip for an aneurysm with the fundus projecting posteromedially, we show that medial aneurysm direction and large size significantly increased risk of infarction.

Generally, during microsurgical clipping of a PCoA aneurysm, the origin of the PCoA is often difficult to see and only the knuckle of the artery proximal to the aneurysm neck can be seen. Further, if the origin of PCoA is low, it is difficult to expose the entire neck in the surgical field of a general pterional approach. The origin of the PCoA is also difficult to identify in some cases; in such cases, an anterior clinoidectomy or cutting of the anterior petroclinoid ligament is performed, as needed. We prefer an extradural anterior clinoidectomy because it permits easier identification of the anatomical orientation, has a shorter procedure time, and can protect intradural structures [30, 31].

In the PCoA aneurysm in medial direction, the origin of PCoA tends to be located more posteriorly and medially. And in these patients, the origin of PCoA, also known as the "knuckle", is almost invisible, and the origin of the PMA is almost hidden by the ICA (Figure 5). Nevertheless, the origin of the PMA can be verified by carefully rotating the ICA after temporary clipping (Figure 6). However, if the aneurysm is large or there is atherosclerosis in the proximal artery, special caution is needed when using this technique. In patients with a large aneurysm or atherosclerosis in the proximal artery, premature aneurysmal rupture, or parent artery dissection can also occur. Hence, in large aneurysms that are medial in direction, the surgeon applies the clip by targeting the area presumed to be the neck of the aneurysm; however, as the origin cannot be clearly identified, both PCoA and PMA flow from the ICA may be occluded or stenosis may occur. Additionally, the course of the PCoA often coincides with the direction of the aneurysm, which may cause the PCoA and the aneurysm to adhere, and if clipping is performed without complete dissection, PCoA torsion will occur, resulting in perforator infarction. Therefore, it is important to ensure patency through various spaces even if the surgeon judges that the clip has been accurately placed. Flow should also be checked near the neck of the aneurysm and in the opticocarotid triangle because the patency of PCoA can be checked using doppler and ICG. However, doppler measurement results may vary depending on arterial diameter, vessel wall thickness, and probe-vessel angle. Additionally, even if flow is seen during ICG video angiography, it may actually be backflow from the posterior cerebral artery, implying that the results from these methods alone cannot guarantee efficient blood supply to all the perforating arteries of the PCoA [5]. When unsure of the relationship between the tip of the blade and perforators, the surgeon can alternatively use an endoscope $[6,11,13,22]$. Yoshioka et al. have suggested that the endoscope can reveal the medial aspect of the aneurysm and enable perforator dissection, even at dead angles of the microscope, during PCoA aneurysm surgery [32]. 
Surgeons often use the curved clip or the j-shaped clip for complete occlusion of a PCoA aneurysm as the slight curve of the clip helps eliminate a "dog-ear" adjacent to the ICA [17]. However, in patients with a medial aneurysm, the use of a curved clip is likely to be a factor in the occlusion of the PCOA or the PMA. A fenestration clip is sometimes used when the aneurysm is large and the aneurysm sac is oriented in the posterior medial direction, i.e., opposite to the surgical field of view. Importantly, greater attention is required in such cases. If the parent artery displays atherosclerotic change, the diameter of the ICA itself, as well as that of the PCoA origin, may be narrowed after clipping. Occasionally, the origin of the anterior choroidal artery is also narrowed and a wide range of ischemic insults may occur (Figure 4).

SEP evaluation during clipping surgery monitors the dorsal column pathway responsible for proprioception and vibration sensation among somatosensory sensations and it is sensitive enough to detect changes in the motor nervous system [14]. However, as SEP monitors the posterolateral tract of the thalamus, it is possible that infarctions in the anterior thalamus may not be apparent intraoperatively. Thus, we hypothesized that SEP change would not have been observed in patients, except for patient\#15, who only showed a transient SEP change. In contrast, intraoperative MEP monitoring can detect neurophysiological changes in the motor cortex and in corticospinal tract function, and because monitoring changes in sensory function is more difficult than evaluating changes in motor function, surgeons usually pay attention to motor function monitoring during aneurysm surgery. In our cohort, two patients (\#8 and \#27) showed false-negative results during EP monitoring and we have previously reported the incidence of false positive cases (0.99\%) and false negative cases (0.53\%) [3]. Mechanisms underlying false-negative EP observations include (1) direct stimulation of deeper structures within the subcortical motor pathway that bypass the ischemic lesion, (2) motor weakness from a lesion that is not located in the corticospinal pathway, and (3) motor weakness without a neurophysiological change in the axons of the corticospinal pathway.

An infarction in the anterior thalamus, which is mainly supplied by the PMA, can lead to abulia, apathy, decrease in general intelligence, impairment of anterograde memory, and disorientation $[9,18,23]$. This could have contributed to the observed increase in the length of hospitalization in the PMA infarction group. Further, depending on individual anatomical variations, only a part of the internal capsule could be supplied, which may manifest as a specific neurologic deficit and a significant difference in GOS at discharge. However, as the results of this study showed no significant difference in GOS at 6 months, permanent morbidity due to PMA infarction could be less serious than other perforator injuries, such as an anterior choroidal artery or lenticulostriate artery, probably because the PMA can supply a portion of the anterior choroidal territorial or lenticulostriate artery territory, which can then form collaterals with the existing anterior choroidal artery or the lenticulostriate artery. However, apart from prominent motor deficits such as hemiparesis, behavioral symptoms, such as inactivity and depression, persisted in most patients despite adequate rehabilitation. Moreover, disturbances in verbal memory or learning have been reported, which make it difficult to return to work $[2,15]$.

There are some limitations in our study. First, selection biases inherent to a single-center, retrospective analysis are applicable. Next, the rapid growth of endovascular treatment technology during the 13 years of data collection may have led to differences in enrollment criteria for microsurgical clipping between the beginning and the end of the study. However, overall, about $15 \%$ of the 5000 patients who were treated with microsurgical clipping in our center had a PCoA aneurysm. This is similar to the incidence (about $10-15 \%$ ) of PCoA aneurysms $[28,29]$, indicating that that selection bias is probably relatively small. Second, given that PMA infarction induces symptoms such as abulia and apathy, rather than weakness, the modified Rankin scale and GOS, which are often used as prognostic evaluations, may not accurately reflect prognosis. Symptoms associated with PMA infarction can be evaluated more objectively through other tools, such as the Mini-Mental state examination, Wechsler adult intelligence scale, apathy evaluation scale $[4,16]$ and the Lille apathy scale [25]. In this study, these evaluations could not be performed due to a lack of records. Thus, multicenter, prospective studies and objective evaluation of outcomes using the above-mentioned evaluation tools are needed.

\section{Conclusion}


PMA infarction can occur after microsurgical clipping of a PCoA aneurysm. As size of the aneurysm and medial direction are risk factors for PMA infarction after clipping of unruptured PCoA aneurysm, meticulous dissection is warranted in such patients, along with thorough patency verification of both the PCoA and the PMA using multiple methods.

\section{Declarations}

\section{Funding}

This work was supported by the National Research Foundation of Korea (NRF) grant funded by the government of Korea (2020R1C1C1004365), and 2020IP0017 and 2019IL0818 from the Asan Institute for Life Sciences, Asan Medical Center, Seoul Korea.

\section{Conflicts of interest}

There are no conflicts of interest to declare.

\section{Availability of data and material}

The authors confirm that the data supporting the findings of this study are available within its supplementary materials. The online version contains supplementary material available at https://doi.org/10.6084/m9.figshare.16866229

\section{Code availability}

Statistical analyses were performed using SAS package (version 9.4, SAS Institute, Cary, USA).

\section{Ethic approval}

This study was performed in line with the principles of the Declaration of Helsinki. The study protocol and the retrospective review of medical records were approved by the institutional review board of the Asan Medical Center, University of Ulsan College of Medicine, Seoul, Korea. ( S2021-0693-0001).

\section{Consent to participate}

For this type of retrospective study, formal consent from patients is not required.

\section{Consent to publication}

For this type of retrospective study, formal consent from patients is not required.

\section{Authors' contributions}

Jong Min Lee M.D. (first author) conceived and designed the analysis, collected the data, contributed data or analysis tools, performed the analysis, and wrote the paper, and other contribution. Joon Ho Byun M.D conceived and designed the analysis, collected the data, contributed data or analysis tools, performed the analysis, wrote the paper, and thoroughly reviewed the manuscript and made corrections. Seungjoo Lee, M.D, Ph.D conceived and designed the analysis, collected the data, contributed data or analysis tools, performed the analysis, wrote the paper, and other contribution. Eun Suk Park M.D, Ph.D conceived and designed the analysis, reviewed the manuscript and made corrections. Jung Cheol Park M.D, Ph.D conceived and designed the analysis, collected the data, contributed data or analysis tools, performed the analysis, wrote the paper, and thoroughly reviewed the manuscript and made corrections. Jae Sung Ahn, M.D, Ph.D conceived and designed the analysis, collected the data, contributed data or analysis tools, performed the analysis, wrote the paper, and other contribution. Wonhyoung Park, M.D., Ph.D. (corresponding author) conceived and designed the analysis, collected the data, contributed data or analysis tools, performed the analysis, wrote the paper, and thoroughly reviewed the manuscript and made corrections. All authors read and approved the final manuscript. 


\section{References}

1. Avci E, Bademci G, Ozturk A (2005) Posterior communicating artery: from microsurgical, endoscopic and radiological perspective. Minim Invasive Neurosurg 48:218-223. https://doi.org/10.1055/s-2005-870963

2. Bogousslavsky J, Regli F, Assal G (1986) The syndrome of unilateral tuberothalamic artery territory infarction. Stroke 17:434-441. https://doi.org/10.1161/01.str.17.3.434

3. Chung J, Park W, Hong SH et al. (2018) Intraoperative use of transcranial motor/sensory evoked potential monitoring in the clipping of intracranial aneurysms: evaluation of false-positive and false-negative cases. J Neurosurg 130:936948. https://doi.org/10.3171/2017.8.JNS17791

4. Clarke DE, Reekum R, Simard M, Streiner DL, Freedman M, Conn D (2007) Apathy in dementia: an examination of the psychometric properties of the apathy evaluation scale. J Neuropsychiatry Clin Neurosci 19:57-64. https://doi.org/10.1176/jnp.2007.19.1.57

5. Endo H, Sato K, Kondo R, Matsumoto Y, Takahashi A, Tominaga T (2012) Tuberothalamic artery infarctions following coil embolization of ruptured posterior communicating artery aneurysms with posterior communicating artery sacrifice. AJNR Am J Neuroradiol 33:500-506. https://doi.org/10.3174/ajnr.A2828

6. Fischer J, Mustafa H (1994) Endoscopic-guided clipping of cerebral aneurysms. Br J Neurosurg 8:559-565. https://doi.org/10.3109/02688699409002948

7. Fukuta S, Hikita C, Iwasaki M et al. (2021) Risk factors for recurrence after coil embolization for internal carotid arteryposterior communicating artery aneurysms. Interdiscip Neurosurg 24:101097.

https://doi.org/10.1016/j.inat.2021.101097

8. Gabrovsky S, Laleva M, Gabrovsky N (2010) The premamillary artery: a microanatomical study. Acta Neurochir (Wien) 152:2183-2189. https://doi.org/10.1007/s00701-010-0763-x

9. Ghika-Schmid F, Bogousslavsky J (2000) The acute behavioral syndrome of anterior thalamic infarction: a prospective study of 12 cases. Ann Neurol 48:220-227. https://doi.org/10.1002/1531-8249(200008)48:2<220::AID-

ANA12>3.0.C0;2-M

10. Golshani K, Ferrell A, Zomorodi A, Smith TP, Britz GW (2010) A review of the management of posterior communicating artery aneurysms in the modern era. Surg Neurol Int 1:88. https://doi.org/10.4103/2152-7806.74147

11. Kalavakonda C, Sekhar LN, Ramachandran P, Hechl P (2002) Endoscope-assisted microsurgery for intracranial aneurysms. Neurosurgery 51:1119-1127. https://doi.org/10.1097/00006123-200211000-00004

12. Kim SH, Yeo DK, Shim JJ, Yoon SM, Chang JC, Bae HG (2015) Morphometric study of the anterior thalamoperforating arteries. J Korean Neurosurg Soc 57:350-358. https://doi.org/10.3340/jkns.2015.57.5.350

13. Kinouchi H, Yanagisawa T, Suzuki A et al. (2004) Simultaneous microscopic and endoscopic monitoring during surgery for internal carotid artery aneurysms. J Neurosurg 101:989-995. https://doi.org/10.3171/jns.2004.101.6.0989

14. Koo YS, Kim DY (2019) Basic principles and practices of evoked potential for intraoperative neurophysiological monitoring: motor evoked potential and somatosensory evoked potential. J Intraoper Neurophysiol 1:14-24. https://doi.org/10.33523/join.2019.1.1.14

15. Kotila M, Hokkanen L, Laaksonen R, Valanne L (1994) Long-term prognosis after left tuberothalamic infarction: a study of 7 cases. Cerebrovasc Dis 4:44-50. https://doi.org/10.1159/000108449

16. Lane-Brown AT, Tate RL (2009) Measuring apathy after traumatic brain injury: Psychometric properties of the Apathy Evaluation Scale and the Frontal Systems Behavior Scale. Brain Inj 23:999-1007. https://doi.org/10.3109/02699050903379347

17. Mason AM, Barrow DL (2018) Anterior circulation aneurysms. In: Ellenbogen RG, Sekhar LN, Kitchen ND, Silva HBd (eds) Principles of neurological surgery 4th edn. Elsevier, pp 264-281 
18. Nishio Y, Hashimoto M, Ishii K, Mori E (2011) Neuroanatomy of a neurobehavioral disturbance in the left anterior thalamic infarction. J Neurol Neurosurg Psychiatry 82:1195-1200. https://doi.org/10.1136/jnnp.2010.236463

19. Noguchi A, Balasingam V, Shiokawa Y, McMenomey SO, Delashaw JB, Jr. (2005) Extradural anterior clinoidectomy: technical note. J Neurosurg 102:945-950. https://doi.org/10.3171/jns.2005.102.5.0945

20. Pedroza A, Dujovny M, Artero JC et al. (1987) Microanatomy of the posterior communicating artery. Neurosurgery 20:228-235. https://doi.org/10.1227/00006123-198702000-00005

21. Pedroza A, Dujovny M, Cabezudo-Artero J et al. (1987) Microanatomy of the premamillary artery. Acta Neurochir (Wien) 86:50-55. https://doi.org/10.1007/BF01419504

22. Perneczky A, Fries G (1998) Endoscope-assisted brain surgery: part 1-evolution, basic concept, and current technique. Neurosurgery 42:219-224. https://doi.org/10.1097/00006123-199802000-00001

23. Rikhye RV, Wimmer RD, Halassa MM (2018) Toward an integrative theory of thalamic function. Annu Rev Neurosci 41:163-183. https://doi.org/10.1146/annurev-neuro-080317-062144

24. Saeki N, Rhoton AL, Jr. (1977) Microsurgical anatomy of the upper basilar artery and the posterior circle of Willis. J Neurosurg 46:563-578. https://doi.org/10.3171/jns.1977.46.5.0563

25. Sockeel P, Dujardin K, Devos D, Deneve C, Destee A, Defebvre L (2006) The Lille apathy rating scale (LARS), a new instrument for detecting and quantifying apathy: validation in Parkinson's disease. J Neurol Neurosurg Psychiatry 77:579-584. https://doi.org/10.1136/jnnp.2005.075929

26. Takahashi JA, Kawarazaki A, Hashimoto N (2004) Intradural en-bloc removal of the anterior clinoid process. Acta Neurochir (Wien) 146:505-509. https://doi.org/10.1007/s00701-004-0249-9

27. Tanabe J, Ishikawa T, Moroi J, Sakata Y, Hadeishi H (2018) Impact of right-sided aneurysm, rupture status, and size of aneurysm on perforator infarction Following microsurgical clipping of posterior communicating artery aneurysms with a distal transsylvian approach. World Neurosurg 111:e905-e911. https://doi.org/10.1016/j.wneu.2018.01.002

28. Ucas Japan Investigators (2012) The natural course of unruptured cerebral aneurysms in a Japanese cohort. N Engl J Med 366:2474-2482. https://doi.org/10.1056/NEJMoa1113260

29. Wiebers DO, Whisnant JP, Huston J, 3rd et al. (2003) Unruptured intracranial aneurysms: natural history, clinical outcome, and risks of surgical and endovascular treatment. Lancet 362:103-110. https://doi.org/10.1016/s01406736(03)13860-3

30. Yang Y, Wang H, Shao Y, Wei Z, Zhu S, Wang J (2006) Extradural anterior clinoidectomy as an alternative approach for optic nerve decompression: anatomic study and clinical experience. Neurosurgery 59:ONS253-262.

https://doi.org/10.1227/01.NEU.0000236122.28434.13

31. Yonekawa Y, Ogata N, Imhof HG et al. (1997) Selective extradural anterior clinoidectomy for supra- and parasellar processes: technical note. J Neurosurg 87:636-642. https://doi.org/10.3171/jns.1997.87.4.0636

32. Yoshioka H, Kinouchi H (2015) The roles of endoscope in aneurysmal surgery. Neurol Med Chir (Tokyo) 55:469-478. https://doi.org/10.2176/nmc.ra.2014-0428

\section{Tables}

Table 1. Baseline characteristics of the study cohort 


\begin{tabular}{|c|c|c|c|}
\hline \multirow[t]{2}{*}{ group } & Normal & PMA infarction & \multirow[t]{2}{*}{$\mathrm{p}$} \\
\hline & $(\mathrm{N}=515)$ & $(N=31)$ & \\
\hline Age & $59.8 \pm 9.1$ & $63.1 \pm 6.4$ & 0.011 \\
\hline \multicolumn{3}{|l|}{ Sex } & \multirow[t]{3}{*}{0.400} \\
\hline Female & $446(86.6 \%)$ & $29(93.5 \%)$ & \\
\hline Male & $69(13.4 \%)$ & $2(6.5 \%)$ & \\
\hline \multicolumn{3}{|l|}{ Hypertension } & \multirow[t]{3}{*}{1.000} \\
\hline no & $248(48.2 \%)$ & $15(48.4 \%)$ & \\
\hline yes & $267(51.8 \%)$ & $16(51.6 \%)$ & \\
\hline \multicolumn{3}{|l|}{ Diabetes } & \multirow[t]{3}{*}{0.469} \\
\hline no & $462(89.7 \%)$ & $26(83.9 \%)$ & \\
\hline yes & $53(10.3 \%)$ & $5(16.1 \%)$ & \\
\hline \multicolumn{4}{|l|}{ Hyperlipidemia } \\
\hline no & 397 (77\%) & $24(77.4 \%)$ & 1.000 \\
\hline yes & $118(23 \%)$ & $7(22.6 \%)$ & \\
\hline \multicolumn{3}{|l|}{ Smoking } & \multirow[t]{3}{*}{0.539} \\
\hline no & $474(92.0 \%)$ & $30(96.8 \%)$ & \\
\hline yes & $41(8.0 \%)$ & $1(3.2 \%)$ & \\
\hline \multicolumn{3}{|l|}{ Stroke history } & \multirow[t]{3}{*}{0.481} \\
\hline no & $493(95.7 \%)$ & $31(100.0 \%)$ & \\
\hline yes & $22(4.3 \%)$ & $0(0.0 \%)$ & \\
\hline Length of hospital stay (day) & $6.5 \pm 2.6$ & $10.3 \pm 9.1$ & $<0.0001$ \\
\hline \multicolumn{4}{|l|}{ Location } \\
\hline Right & $246(47.7 \%)$ & $11(35.5 \%)$ & 0.252 \\
\hline Left & $269(52.3 \%)$ & $20(64.5 \%)$ & \\
\hline Size (mm) & $4.9 \pm 2.4$ & $7.3 \pm 4.7$ & $<0.0001$ \\
\hline \multicolumn{4}{|l|}{ PCoA type } \\
\hline - Adult & $220(42.7 \%)$ & $10(32.2 \%)$ & 0.0371 \\
\hline - Fetal & $182(35.3 \%)$ & $8(25.8 \%)$ & \\
\hline - Hypoplasia & $113(21.9 \%)$ & $13(41.9 \%)$ & \\
\hline \multicolumn{4}{|l|}{ Aneurysm direction } \\
\hline - Inferior & $140(27.1 \%)$ & $6(19.3 \%)$ & 0.0002 \\
\hline - Medial & $19(3.7 \%)$ & $6(19.3 \%)$ & \\
\hline - Posterior & $356(69.1 \%)$ & 19 (61.3\%) & \\
\hline
\end{tabular}




\begin{tabular}{|c|c|c|c|}
\hline \multirow[t]{2}{*}{ group } & Normal & PMA infarction & \multirow[t]{2}{*}{$\mathrm{p}$} \\
\hline & $(\mathrm{N}=515)$ & $(N=31)$ & \\
\hline \multicolumn{3}{|l|}{ Using fenestration clip } & \multirow[t]{3}{*}{$<0.001$} \\
\hline no & $488(94.8 \%)$ & $23(74.2 \%)$ & \\
\hline yes & $27(5.2 \%)$ & $8(25.8 \%)$ & \\
\hline \multicolumn{3}{|l|}{ Intraoperative rupture } & \multirow[t]{3}{*}{1.000} \\
\hline no & $505(98.1 \%)$ & $30(96.8 \%)$ & \\
\hline yes & $10(1.9 \%)$ & $1(3.2 \%)$ & \\
\hline \multicolumn{4}{|l|}{ GOS at discharge } \\
\hline 3 & $0(0 \%)$ & $2(6.5 \%)$ & $<0.0001$ \\
\hline 4 & $0(0 \%)$ & $5(16.1 \%)$ & \\
\hline 5 & $515(100 \%)$ & $24(77.4 \%)$ & \\
\hline \multicolumn{4}{|l|}{ GOS at 6 months } \\
\hline 3 & $0(0 \%)$ & $0(0 \%)$ & 0.0568 \\
\hline 4 & $0(0 \%)$ & $1(3.2 \%)$ & \\
\hline 5 & $515(100 \%)$ & $30(96.8 \%)$ & \\
\hline
\end{tabular}

Abbreviations: PMA, premammillary artery; PCoA, posterior communicating artery; GOS, glasgow outcome scale

Table 2 Summary of cases with PMA infarction after PCoA aneurysm clipping 


\begin{tabular}{|c|c|c|c|c|c|c|c|c|}
\hline $\begin{array}{l}\text { Patient } \\
\text { No. }\end{array}$ & Age/Sex & $\begin{array}{l}\text { Aneurysm } \\
\text { size (mm) }\end{array}$ & $\begin{array}{l}\text { Aneurysm } \\
\text { direction }\end{array}$ & $\begin{array}{l}\text { Territory of } \\
\text { ischemia }\end{array}$ & $\begin{array}{l}\text { Ischemic } \\
\text { symptom }\end{array}$ & $\begin{array}{l}\text { EP } \\
\text { change }\end{array}$ & $\begin{array}{l}\mathrm{mRS} \text { at } \\
\text { discharge }\end{array}$ & $\begin{array}{l}\mathrm{mRS} \\
\text { at } \\
6 \\
\text { months }\end{array}$ \\
\hline 1 & $66 / F$ & 7.6 & Posterior & Hypothalamus & None & $\begin{array}{l}\text { Not } \\
\text { performed }\end{array}$ & 4 & 5 \\
\hline 2 & $59 / F$ & 9.0 & Medial & $\begin{array}{l}\text { Hypothalamus, } \\
\text { head of } \\
\text { caudate } \\
\text { nucleus }\end{array}$ & Hemiparesis & $\begin{array}{l}\text { Not } \\
\text { performed }\end{array}$ & 5 & 5 \\
\hline 3 & $60 / F$ & 22.0 & Posterior & Hypothalamus & None & $\begin{array}{l}\text { Not } \\
\text { performed }\end{array}$ & 5 & 5 \\
\hline 4 & $71 / F$ & 10.8 & Posterior & $\begin{array}{l}\text { Inferior } \\
\text { caudate } \\
\text { nucleus head }\end{array}$ & Confusion & $\begin{array}{l}\text { Not } \\
\text { performed }\end{array}$ & 4 & 5 \\
\hline 5 & $66 / F$ & 7.8 & Posterior & $\begin{array}{l}\text { Anterior } \\
\text { thalamus }\end{array}$ & None & $\begin{array}{l}\text { Not } \\
\text { performed }\end{array}$ & 5 & 5 \\
\hline 6 & $67 / F$ & 3.6 & Medial & $\begin{array}{l}\text { Anterior } \\
\text { thalamus }\end{array}$ & None & None & 5 & 5 \\
\hline 7 & $73 / \mathrm{M}$ & 5.4 & Posterior & $\begin{array}{l}\text { Posterior limb } \\
\text { of internal } \\
\text { capsule }\end{array}$ & $\begin{array}{l}\text { Hemiparesis } \\
\text { (POD 3) }\end{array}$ & None & 4 & 5 \\
\hline 8 & $62 / F$ & 3.8 & Medial & $\begin{array}{l}\text { Anterior } \\
\text { thalamus, genu } \\
\text { and posterior } \\
\text { limb of Internal } \\
\text { capsule }\end{array}$ & $\begin{array}{l}\text { Right upper } \\
\text { limb } \\
\text { weakness }\end{array}$ & None & 4 & 5 \\
\hline 9 & $57 / F$ & 12.9 & Posterior & $\begin{array}{l}\text { Anterior } \\
\text { thalamus }\end{array}$ & None & $\begin{array}{l}\text { Transient } \\
\text { MEP } \\
\text { change }\end{array}$ & 5 & 5 \\
\hline 10 & $60 / F$ & 19.4 & Medial & Basal ganglia & confusion & None & 5 & 5 \\
\hline 11 & $58 / F$ & 5.1 & Posterior & $\begin{array}{l}\text { Anterior } \\
\text { thalamus }\end{array}$ & None & None & 5 & 5 \\
\hline 12 & $68 / F$ & 4.8 & Posterior & $\begin{array}{l}\text { Anterior } \\
\text { thalamus }\end{array}$ & None & None & 5 & 5 \\
\hline 13 & $54 / F$ & 3.8 & Posterior & $\begin{array}{l}\text { Anterior } \\
\text { thalamus }\end{array}$ & None & None & 5 & 5 \\
\hline 14 & $59 / F$ & 3.7 & Posterior & $\begin{array}{l}\text { Hypothalamus, } \\
\text { Anterior } \\
\text { thalamus }\end{array}$ & confusion & None & 5 & 5 \\
\hline 15 & $57 / F$ & 4.0 & Lateral & $\begin{array}{l}\text { Anterior } \\
\text { thalamus }\end{array}$ & None & $\begin{array}{l}\text { Transient } \\
\text { MEP, SEP } \\
\text { change }\end{array}$ & 5 & 5 \\
\hline 16 & $61 / M$ & 7.6 & Posterior & Hypothalamus & None & None & 5 & 5 \\
\hline 17 & $74 / F$ & 15.3 & Posterior & $\begin{array}{l}\text { Anterior } \\
\text { thalamus, genu } \\
\text { and posterior } \\
\text { limb of internal } \\
\text { capsule }\end{array}$ & Hemiparesis & $\begin{array}{l}\text { Persistent } \\
\text { MEP } \\
\text { change }\end{array}$ & 3 & 5 \\
\hline
\end{tabular}




\begin{tabular}{|c|c|c|c|c|c|c|c|c|}
\hline 18 & $60 / F$ & 8.9 & Posterior & $\begin{array}{l}\text { Genu of } \\
\text { Internal } \\
\text { capsule }\end{array}$ & None & None & 5 & 5 \\
\hline 19 & $57 / F$ & 2.7 & Posterior & $\begin{array}{l}\text { Genu of } \\
\text { internal } \\
\text { capsule }\end{array}$ & None & None & 5 & 5 \\
\hline 20 & $64 / F$ & 7.1 & Medial & $\begin{array}{l}\text { Anterior } \\
\text { thalamus }\end{array}$ & None & None & 5 & 5 \\
\hline 21 & $72 / F$ & 5.8 & Lateral & $\begin{array}{l}\text { Anterior } \\
\text { thalamus }\end{array}$ & confusion & None & 4 & 5 \\
\hline 22 & $59 / F$ & 9.7 & Lateral & $\begin{array}{l}\text { Genu of } \\
\text { internal } \\
\text { capsule }\end{array}$ & None & None & 5 & 5 \\
\hline 23 & $64 / F$ & 7.2 & Lateral & $\begin{array}{l}\text { Genu of } \\
\text { internal } \\
\text { capsule }\end{array}$ & None & None & 5 & 5 \\
\hline 24 & $66 / F$ & 3.3 & Posterior & hypothalamus & None & None & 5 & 5 \\
\hline 25 & $62 / F$ & 4.9 & Posterior & hypothalamus & None & None & 5 & 5 \\
\hline 26 & $61 / F$ & 14.1 & Posterior & $\begin{array}{l}\text { Anterior } \\
\text { thalamus }\end{array}$ & None & None & 5 & 5 \\
\hline 27 & $72 / F$ & 7.8 & Medial & $\begin{array}{l}\text { Anterior } \\
\text { thalamus, genu } \\
\text { and posterior } \\
\text { limb of internal } \\
\text { capsule }\end{array}$ & Hemiparesis & None & 3 & 4 \\
\hline 28 & $74 / F$ & 5.0 & Lateral & $\begin{array}{l}\text { Genu of } \\
\text { internal } \\
\text { capsule }\end{array}$ & None & None & 5 & 5 \\
\hline 29 & $46 / F$ & 3.7 & Posterior & $\begin{array}{l}\text { Genu of } \\
\text { internal } \\
\text { capsule }\end{array}$ & None & None & 5 & 5 \\
\hline 30 & $63 / F$ & 5.0 & Posterior & Hypothalamus & None & None & 5 & 5 \\
\hline 31 & $63 / F$ & 8.2 & Lateral & $\begin{array}{l}\text { Hypothalamus, } \\
\text { anterior } \\
\text { thalamus }\end{array}$ & None & None & 5 & 5 \\
\hline
\end{tabular}

Table 3. Univariate analysis of factors that show significant difference between normal and PMA group 


\begin{tabular}{llllll} 
& \multicolumn{5}{l}{ Univariable } \\
\hline Age & & OR & $95 \% \mathrm{Cl}$ & & p-value \\
\hline Aneurysm size & & 1.044 & 1 & 1.092 & 0.0516 \\
\hline Location & Right & 0.601 & 0.282 & 1.281 & 0.1873 \\
\hline & Left & 1 & & & \\
\hline Use of fenestration clip & & 6.287 & 2.574 & 15.354 & $<.0001$ \\
\hline Intraoperative rupture & & 1.683 & 0.209 & 13.587 & 0.625 \\
\hline PCoA type & Adult & & & & $\mathbf{0 . 0 4 5 1}$ \\
\hline & Fetal & 0.967 & 0.374 & 2.501 & 0.9449 \\
\hline Aneurysm direction & Medial & 7.368 & 2.156 & 25.18 & $\mathbf{0 . 0 0 1 4}$ \\
\hline & Posterior & 1.245 & 0.487 & 3.183 & 0.6468 \\
\hline & Lateral & 1 & & & $\mathbf{0 . 0 0 1 5}$
\end{tabular}

Table 4. Multivariate analysis of factors related to PMA infarction after clipping

\begin{tabular}{lllll} 
& OR & $95 \% \mathrm{Cl}$ & & p-value \\
& & & & \\
\hline Size & 1.194 & 1.08 & 1.32 & 0.0005 \\
\hline Direction & 4.615 & 1.224 & 17.406 & 0.0239 \\
- medial & 1.255 & 0.48 & 3.281 & 0.6434 \\
- posterior & 1 & & & 0.0507 \\
- lateral & & & &
\end{tabular}

*Backward elimination method

\section{Figures}




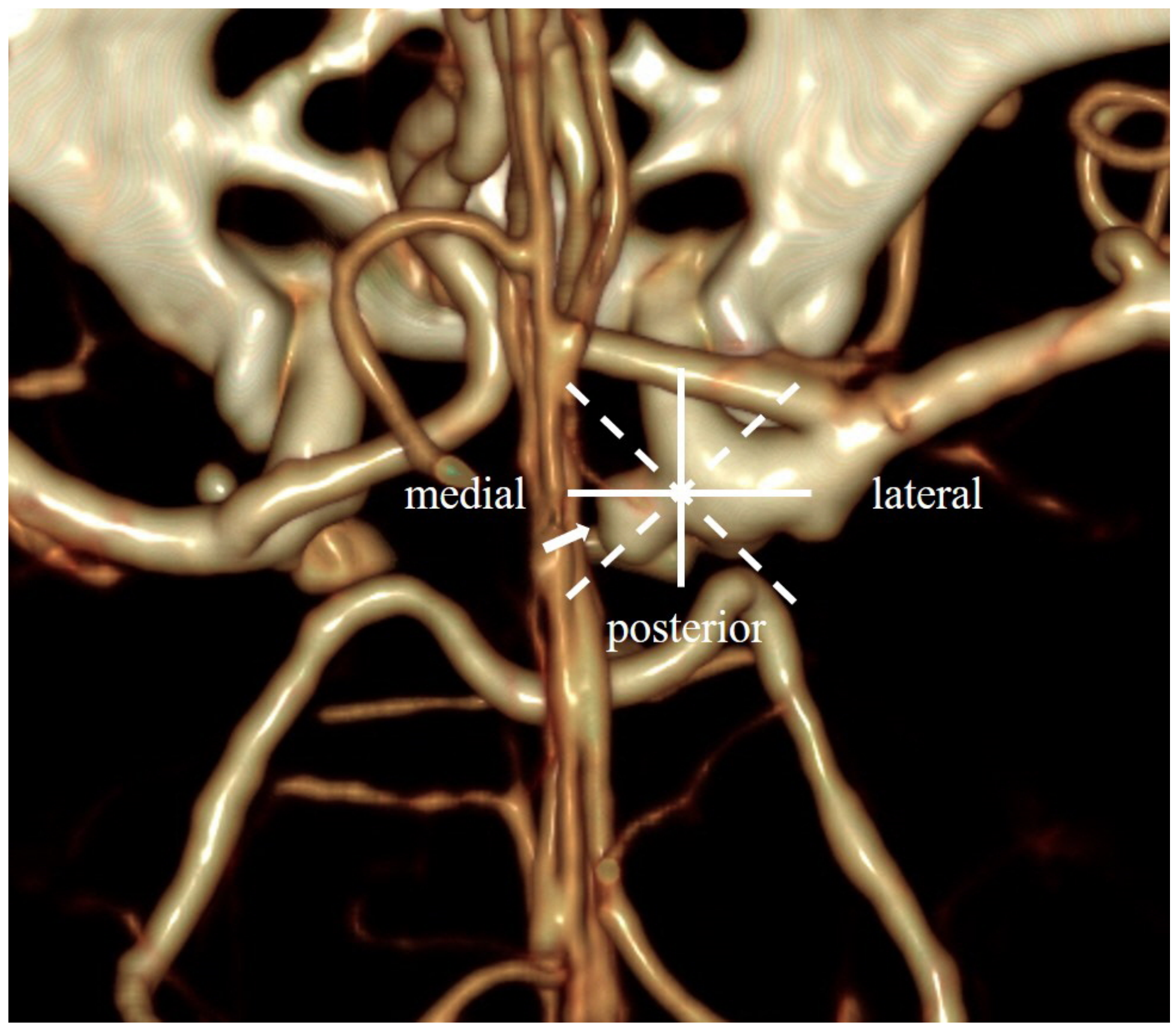

\section{Figure 1}

Three-dimensional computed tomography image, superior view. Third and fourth lines (dotted line) equally divide the angle between the parallel and the perpendicular lines (solid line). Direction of the posterior communicating artery (PCoA) aneurysm was categorized as lateral, posterior, or medial, based on the quadrants separated by dotted lines. The representative aneurysm (white arrow) presented here is medial in direction. 


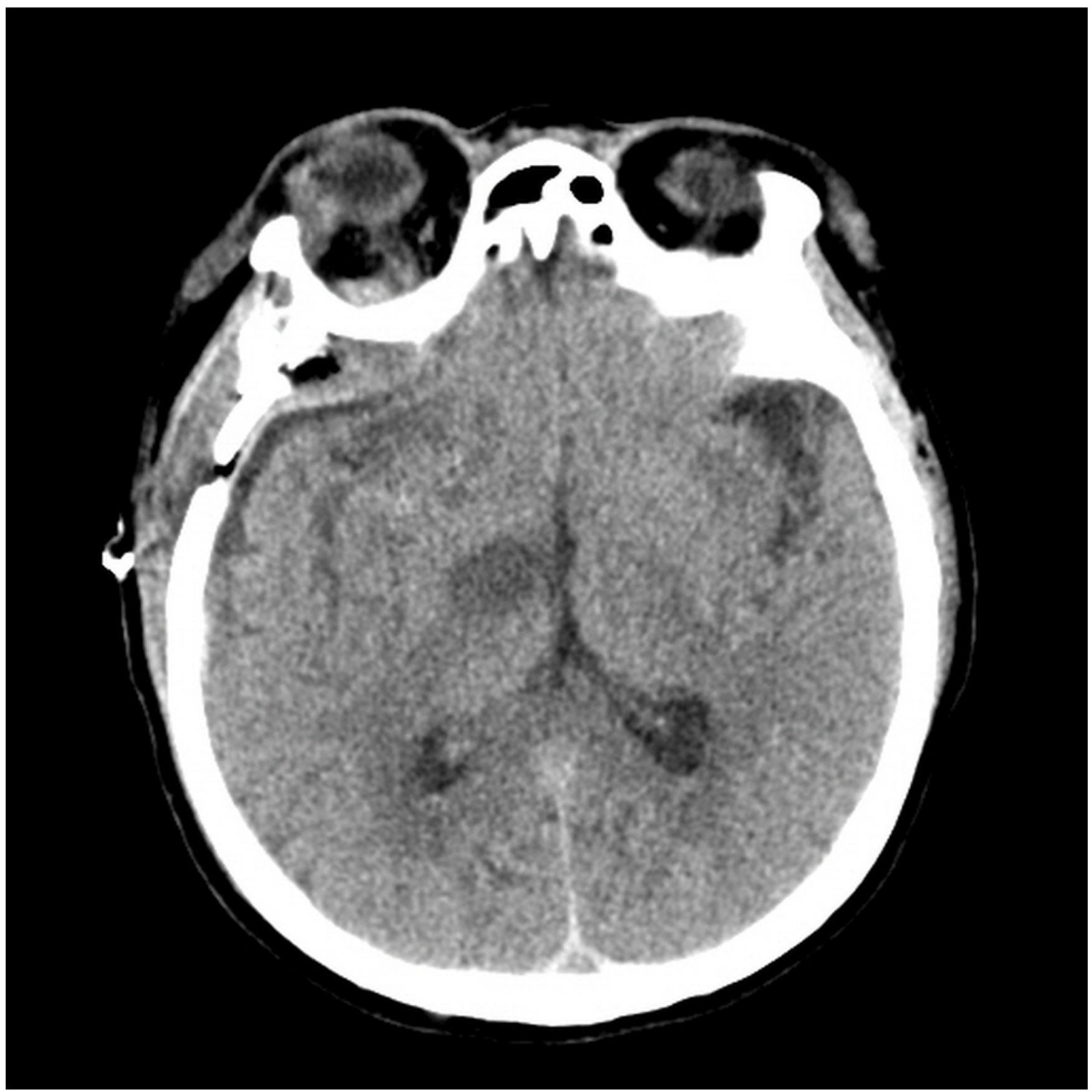

Figure 2

Image of a patient who suffered premammillary artery (PMA) infarction after clipping of unruptured posterior communicating artery (PCoA) aneurysm. The patient suffered mild confusion without any focal neurologic deficit. Postoperative brain computed tomography (CT) scan acquired 3 days after surgery revealed a focal low density at the right anterior thalamus. 


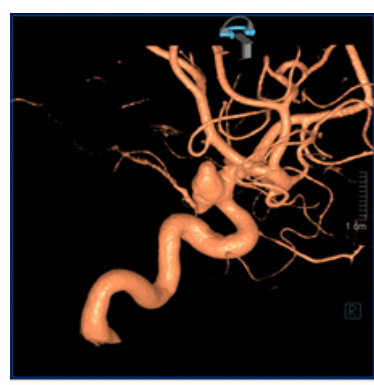

a

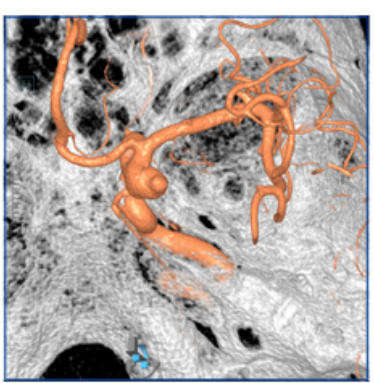

b

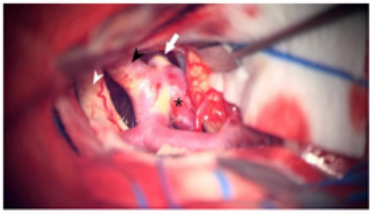

c

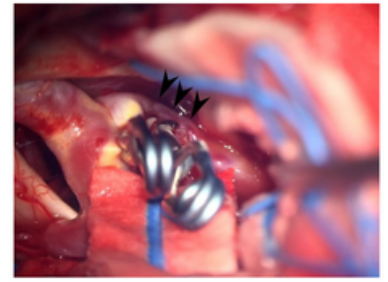

d

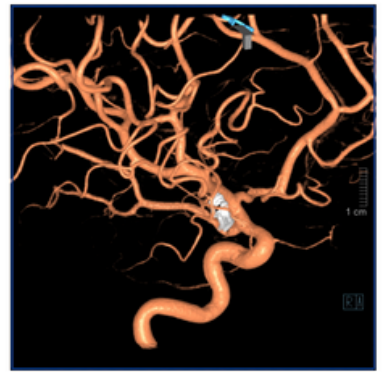

e

Figure 3

Images of a patient who underwent microsurgical clipping for unruptured right posterior communicating artery (PCoA) aneurysm using curved clips. a, preoperative transfemoral cerebral angiography (TFCA); 3-dimensional image shows a unruptured right posterior communicating artery ( $\mathrm{PCOA}$ ) aneurysm. $b, A$ superior side view, the aneurysm is lateral in direction. c, intraoperative photograph. Internal carotid artery (black arrowhead), optic nerve (white arrowhead), PCoA aneurysm (asterisk) and PCoA (white arrow) are shown. d, Intraoperative photograph after clipping. Aneurysm was clipped using two curved clips and PCoA (black arrowhead) is shown with gentle temporal lobe retraction. e, postoperative TFCA 3dimensional image shows a complete obliteration of aneurysm. Note that clip does not affect the diameter of the parent artery.

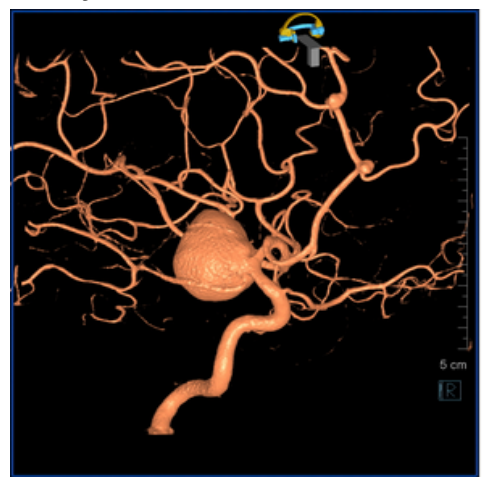

a

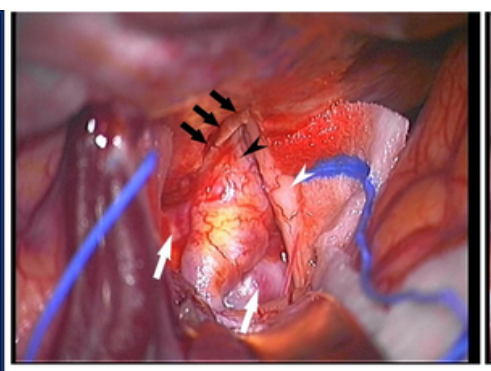

b

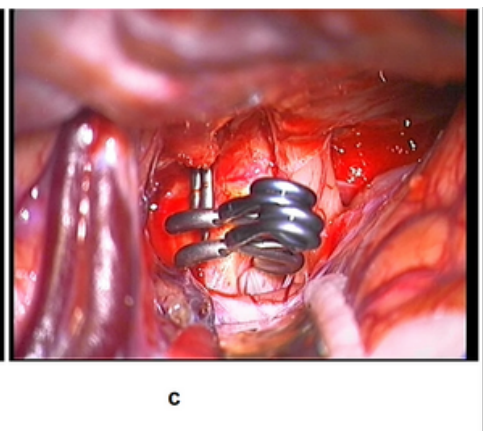

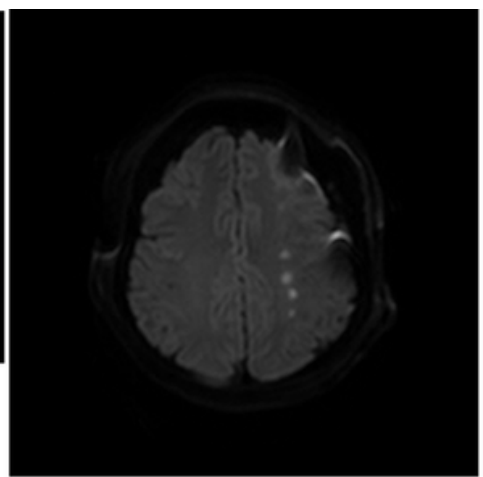

d

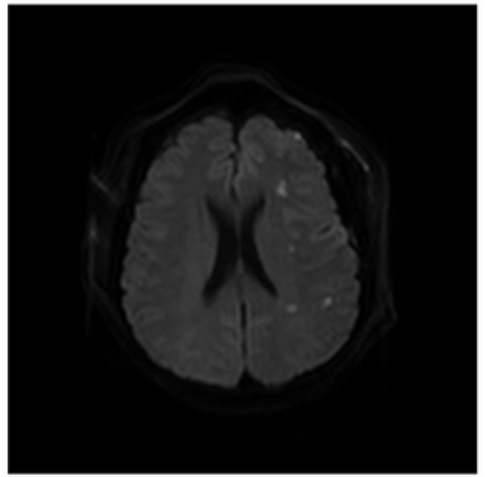

e

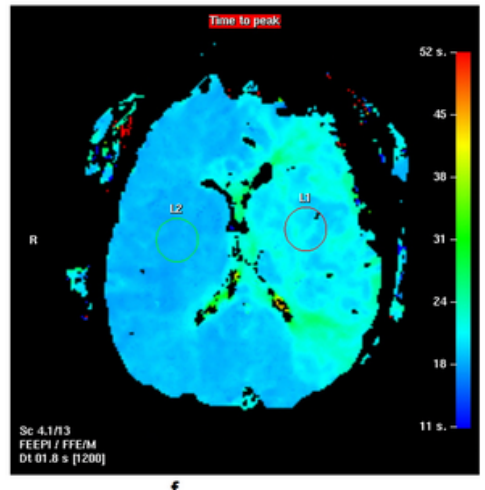

f

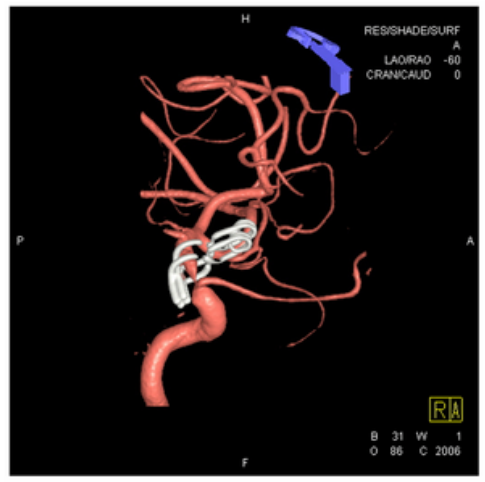

g

\section{Figure 4}

Images and clinical course of a patient who underwent microsurgical clipping of an unruptured left posterior communicating artery (PCoA) aneurysm using fenestration clips. a, preoperative transfemoral cerebral angiography (TFCA), 3-dimensional image shows an unruptured left posterior communicating artery (PCoA) aneurysm. b, Intraoperative photograph. After extradural anterior clinoid process removal, internal carotid artery (ICA) (black arrowhead), optic nerve 
(white arrowhead), PCoA aneurysm (white arrow), and resected distal dural ring (black arrows) are shown. There is also atherosclerotic change in ICA. c, Intraoperative photograph after clipping. Aneurysm was clipped using two fenestration clips. One day after surgery, the patient suffered sudden right hemiparesis. d, e, Diffusion weighted-imaging revealed multifocal diffusion restriction lesions on the watershed zone of deep white matter, suggesting hemodynamic infarction. $f$, Perfusion image confirmed delayed mean transit time in the left hemisphere. g, Postoperative TFCA 3-dimensional imaging shows complete obliteration of the aneurysm. However, note the narrowed ICA. The gap between the clip blade and the internal lumen is most likely due to the atherosclerosis of the ICA.

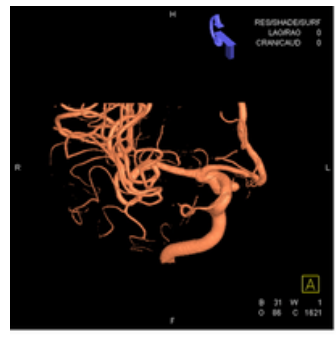

a

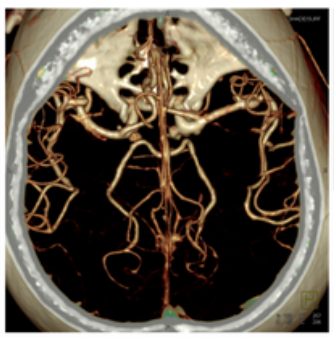

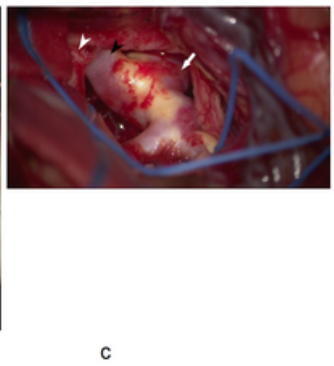

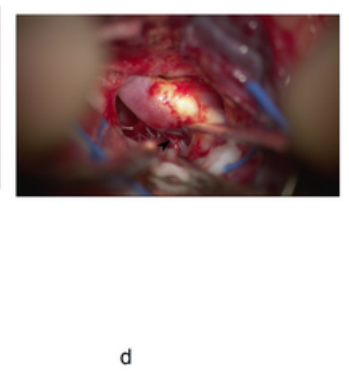

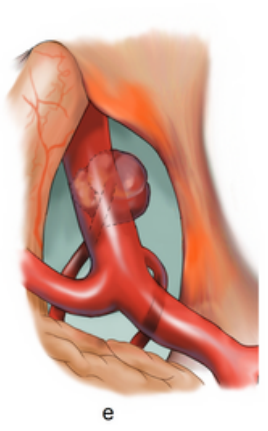

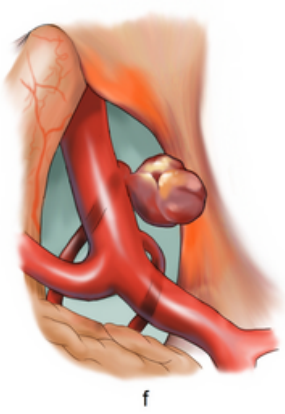

\section{Figure 5}

Images of a patient who underwent microsurgical clipping of an unruptured right posterior communicating artery (PCoA) aneurysm, which was medial in direction. a, preoperative transfemoral cerebral angiography (TFCA) 3-dimensional image shows an unruptured left posterior communicating artery (PCoA) aneurysm. $b$, Superior view, the aneurysm is medial in direction. c, Intraoperative photograph. Internal carotid artery (black arrowhead), optic nerve (white arrowhead), and PCoA aneurysm (white arrow) are shown. In contrast to lateral direction aneurysm (Figure 3), where the origin of posterior communicating artery (PCoA) or "knuckle" was well visible, the origin of PCoA is hardly identified in the medial direction aneurysm because, in a patient with medial direction PCoA aneurysm, the origin of PCoA tends to be located more posteriorly and medially. d, Although the course of PCoA (black arrowhead) can be confirmed through the opticocarotid space, the origin of PCoA, and PMA are rarely confirmed. e, Schematic drawing of medial direction PCoA aneurysm. the origin of PCoA, also known as the "knuckle", is almost invisible and hidden by the ICA. f, Schematic drawing of lateral direction PCoA aneurysm. The origin of PCoA is swell visible. 

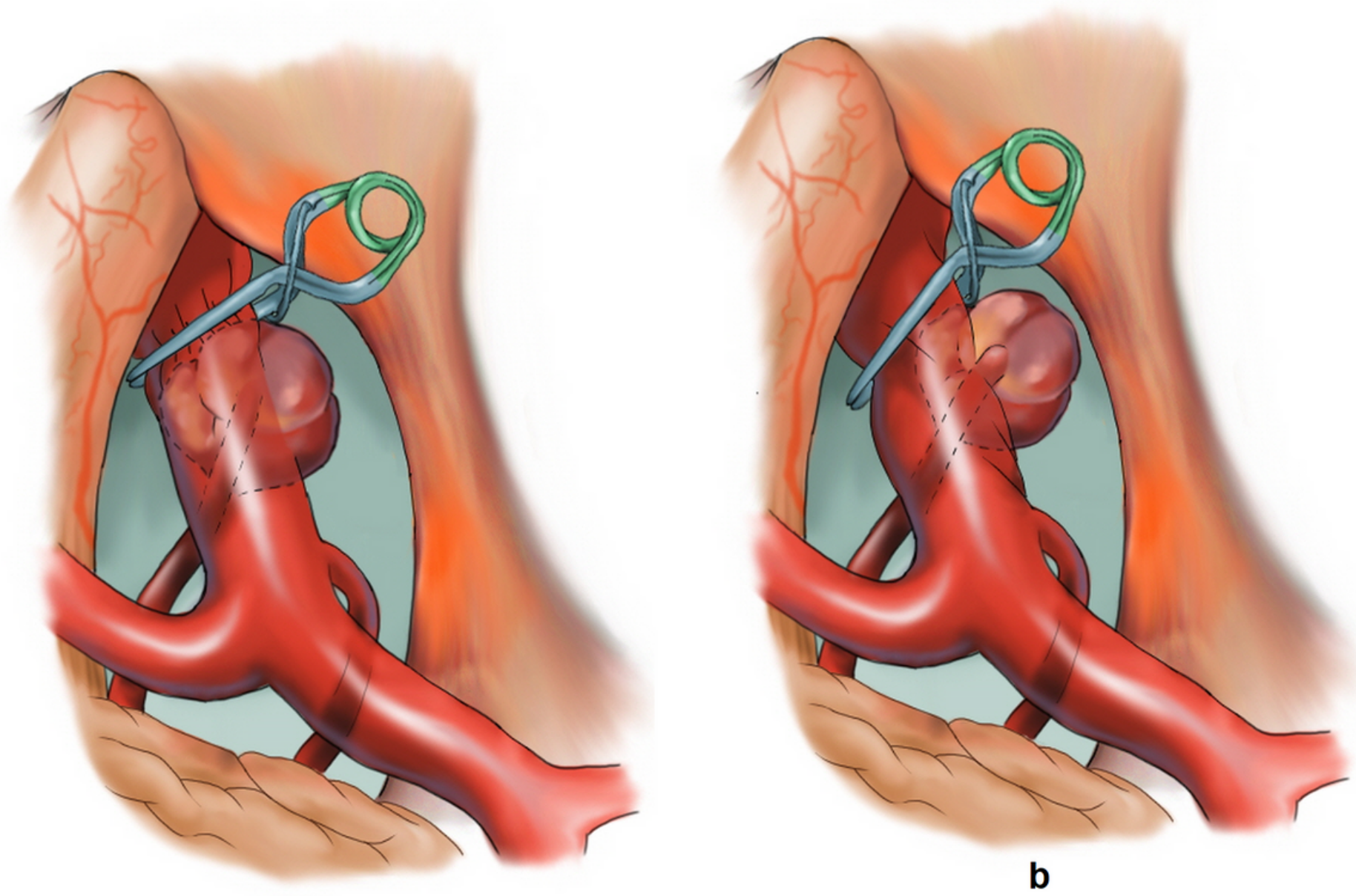

a

\section{Figure 6}

Schematic drawing of rotation technique with temporary clip. a, The origin of posterior communicating artery (PCoA) is hidden by internal carotid artery (ICA). A temporary clip was applied to the ICA as a lever. b, A slight rotation of temporary clip can expose the origin of PCoA.

\section{Supplementary Files}

This is a list of supplementary files associated with this preprint. Click to download.

- data.csv 